\title{
The potential impact of increased treatment rates for alcohol dependence in the United Kingdom in 2004
}

Kevin D Shield ${ }^{1,2^{*}}$, Jürgen Rehm ${ }^{1,2,3,4,5}$, Maximilien X Rehm ${ }^{6}$, Gerrit Gmel ${ }^{1}$ and Colin Drummond ${ }^{7}$

\begin{abstract}
Background: Alcohol consumption has been linked to a considerable burden of disease in the United Kingdom $(U K)$, with most of this burden due to heavy drinking and Alcohol Dependence (AD). However, AD is undertreated in the UK, with only $8 \%$ of those individuals with $A D$ being treated in England and only $6 \%$ of those individuals with AD being treated in Scotland. Thus, the objective of this paper is to quantify the deaths that would have been avoided in the UK in 2004 if the treatment rate for AD had been increased.
\end{abstract}

Methods: Data on the prevalence of AD, alcohol consumption, and mortality were obtained from the Adult Psychiatric Morbidity Survey, the Global Information System on Alcohol and Health, and the 2004 Global Burden of Disease study respectively. Data on the effectiveness of pharmacological treatment and Motivational Interviewing/ Cognitive Behavioural Therapy were obtained from Cochrane reviews and meta-analyses. Simulations were used to model the number of deaths under different treatment scenarios. Sensitivity analyses were performed to model the effects of Brief Interventions and to examine the effect of using AD prevalence data obtained from the National Institute for Health and Clinical Excellence.

Results: In the UK, 320 female and 1,385 male deaths would have been avoided if treatment coverage of pharmacological treatment had been increased to $20 \%$. This decrease in the number of deaths represents $7.9 \%$ of all alcohol-attributable deaths (7.0\% of all alcohol-attributable deaths for women and $8.1 \%$ of all alcohol-attributable deaths for men). If we used lower AD prevalence rates obtained from the National Institute for Health and Clinical Excellence, then treatment coverage of pharmacological treatment in hospitals for $20 \%$ of the population with $A D$ would have resulted in the avoidance of 529 deaths in 2004 (99 deaths avoided for women and 430 deaths avoided for men).

Conclusions: Increasing AD treatment in the UK would have led to a large number of deaths being avoided in 2004. Increased AD treatment rates not only impact mortality but also impact upon the large burden of disability and morbidity attributable to AD, as well as the associated social and economic burdens.

Keywords: Alcohol, Mortality, Alcohol dependence, Alcohol dependence treatment, United Kingdom

\footnotetext{
* Correspondence: Kevin.Shield@mail.utoronto.ca

${ }^{1}$ Centre for Addiction and Mental Health (CAMH), 33 Russell Street, Toronto,

ON M5S 2S1, Canada

${ }^{2}$ Institute of Medical Science, University of Toronto, Toronto, Canada

Full list of author information is available at the end of the article
} 


\section{Background}

Alcohol consumption causes a large burden of disease $[1,2]$, with most of this burden caused by heavy drinking and Alcohol Dependence (AD) [3], where heavy drinking is defined as consuming a daily average of 5 or more standard United Kingdom (UK) drinks for women $(40+$ grams $(\mathrm{g})$ of pure alcohol) and consuming a daily average of 7.5 standard UK drinks or more for men $(60+\mathrm{g}$ of pure alcohol) [4]. In the European Union (EU) in 2004 for people 15 to 64 years of age, it has been estimated that $77.3 \%$ of the net alcohol-attributable burden of mortality, $67.2 \%$ of the detrimental alcohol-attributable burden (i.e., the burden not including the beneficial effects of alcohol for selected ischemic disease categories and diabetes), and $9.2 \%$ of the total burden of mortality resulted from heavy drinking [3]. One of the most severe consequences of alcohol consumption is $\mathrm{AD}$ (defined as a maladaptive behaviour of drinking of alcoholic beverages with clinically relevant consequences) [5]. $\mathrm{AD}$ is strongly associated with frequency of heavy drinking episodes [6,7].

\section{Alcohol consumption in the UK}

In the UK in 2009 the average adult per capita consumption was 12.5 litres (l), the same as the EU (12.5 l), $89.3 \%$ of women and $91.3 \%$ of men were current drinkers (people who consumed alcohol in the past year) [8], and $8.9 \%$ of women and $15.5 \%$ of men were heavy drinkers [8]. Patterns of drinking in the UK are quite detrimental, as indicated by the UK's pattern of drinking score of 3 (out of 5) in 2009, with a high prevalence of regular and irregular heavy drinking occasions [8]. In the UK in 2009 approximately 14\% of drinkers consumed 5 or more drinks several times a week, $20 \%$ consumed 5 or more drinks once a week, and a further $14 \%$ consumed 5 or more drinks once a month [9].

\section{Alcohol dependence in the UK}

In England in 2007 approximately 3.6\% of women and 9.3\% of men 15 to 64 years of age had AD [10]; this translates into more than 2 million people afflicted with $A D$ in England. The National Institute for Health and Clinical Excellence estimated the prevalence of AD to be $2 \%$ for women and $6 \%$ for men [11]. By comparison, the prevalence of $\mathrm{AD}$ in 2005 in the EU was lower than in the UK, with $1.5 \%$ and $5.4 \%$ for women and men 15 to 64 years of age respectively being alcohol dependent [8].

\section{Alcohol-attributable mortality in the UK}

In the UK in 2004 an estimated 13.1 female and 27.6 male deaths (per 100,000 people) among people 15 to 64 years of age were attributable to alcohol consumption [12], with $6.4 \% 8.5 \%$ of all premature deaths among women and men respectively being caused by alcohol consumption. In other words, 1 out of 16 and 1 out of 12 premature deaths of women and men respectively were caused by alcohol consumption.

\section{Alcohol dependence treatment in the UK}

Unfortunately, while there are effective treatment options available, both in terms of psychosocial [13] and pharmacological interventions for AD $[14,15]$, the overall treatment rate for $\mathrm{AD}$ is low (for an overview of various treatment interventions for AD, see [11]). In Europe, less than $10 \%$ of all people with $\mathrm{AD}$ receive treatment in any given year $[8,16]$, and in England it is estimated that $6 \%$ of the population 15 to 64 years of age with AD receive treatment in any given year [17]. In Scotland, where prevalence of AD is higher than in England, treatment coverage is over $8 \%$ [18]. Therefore, given the burden of $\mathrm{AD}$ in the UK and the low treatment coverage rates, increasing treatment rates and applying evidencebased psychosocial and pharmacological interventions could result in considerable reductions in alcohol-attributable mortality in the UK [3]. Thus, the aim of this article is to quantify the effect of increasing $A D$ treatment coverage rates in the UK.

\section{Methods}

\section{Data sources}

Data on drinking status for the UK were obtained from the Global Status Report on Alcohol and Health [19]; for the UK the drinking status estimates were based on large population surveys and government statistics. Data on binge drinking patterns were obtained from the European Commission report and from the World Health Organization $[9,19]$. Per capita consumption of alcohol data were obtained from the Global Information System on Alcohol and Health (http://www.who.int/gho/ alcohol/en/index.html). Pattern of drinking score data were obtained from the 2010 Global Burden of Disease (GBD) study (see [20] for data on drinking pattern scores and per capita consumption by country for 2005). The pattern of drinking score, developed as part of the Comparative Risk Assessment for alcohol within the GBD studies, is a composite measure based on frequency of heavy drinking occasions, the amount consumed per occasion, the proportion of overall consumption due to drinking to intoxication, and the proportion of drinking occasions in combination with meals (see [21] for a definition of patterns of drinking and the construction of a comparative score). Data on AD were obtained from [10], and additional estimates of $\mathrm{AD}$ for the sensitivity analyses were obtained from the National Institute for Health and Clinical Excellence [11]. Mortality data by cause, age, and sex for the UK for 2004 were obtained from the 2004 GBD study [4]. 


\section{Modelling alcohol consumption}

The drinking prevalence of any population can be estimated using sex- and age-specific per capita consumption data; this data is used to derive a Gamma distribution which is used to model the distribution of alcohol consumption. This continuous prevalence distribution, combined with continuous Relative Risk (RR) functions, is used to derive the proportion of deaths attributable to alcohol consumption (the proportion of deaths that would not be present under a counterfactual scenario where no one consumed alcohol) [22,23].

\section{Modelling the effect of interventions for $A D$ on mortality}

Given the low current rate of treatment for people with $\mathrm{AD}$ in the UK, we simulated the potential effects of the following interventions: 1) pharmacological treatment 2) Motivational Interviewing/Cognitive Behavioural Therapy (MI/ $\mathrm{CBT}$ ) and 3) Brief Interventions (BI) (the effects of BI were only used for sensitivity analyses as the estimated effects of BI have limitations (see limitations section) (for a detailed description of the methodology, see Additional file 1).

The effect of treatment interventions for $\mathrm{AD}$ can be expressed as a reduction in average alcohol consumption or a decrease in the risk of mortality. To estimate the effect of increasing treatment coverage for $\mathrm{AD}$ on mortality, we applied a reduction in alcohol consumption to a subset of the population with $\mathrm{AD}$, and compared the estimated Alcohol-Attributable Fractions (defined as the proportion of mortality that would not have occurred if people had never consumed alcohol [24]) for the entire population before and after the increase in $\mathrm{AD}$ treatment coverage rates.

To estimate the effect of MI/CBT, an average drop in consumption of $15.8 \mathrm{~g}$ of pure alcohol per day was assumed (measured against no intervention (using the 95\% Confidence Interval (CI) of $9.6 \mathrm{~g}$ to $21.8 \mathrm{~g}$ )) $[25,26]$. As an upper limit of the effect of MI/CBT, we modelled the effect using an average drop in consumption of $21.8 \mathrm{~g}$ of pure alcohol per day, i.e., the upper limit of the 95\% CI. We combined CBT and MI, as the meta-analyses on their effectiveness yielded almost identical results. In addition, Project Matching alcoholism treatment to client heterogeneity did not observe any significant differences between the use of either MI or CBT [27]. To estimate the effects of pharmacological therapy for $\mathrm{AD}$, we combined the effects of randomized controlled trials for acamprosate and opioid antagonist therapy $[14,15]$ by calculating the difference in alcohol consumption between baseline and follow-up in the group that received medication. The estimated effect was for the patient population that received the pharmacological therapy; $55.0 \%$ reduced their alcohol consumption by an average of $13 \%$ (18.1\% of the patient population reduced their drinking by $50 \%$ and $26.8 \%$ of the population achieved abstinence).
To estimate the effect of BI in hospital settings, two different estimates were modelled. The first approach was based on an estimated reduction in consumption of $13.5 \mathrm{~g}$ of pure alcohol per day from the meta-analysis (using a 95\% CI of $2.7 \mathrm{~g}$ to $24.5 \mathrm{~g}$ ) [28,29] (this treatment is represented by the term BI (1)). The second approach was to assume an average RR for mortality of 0.6 (95\% $\mathrm{CI}$ of 0.40 to 0.91 ) for people with $\mathrm{AD}$ who received $\mathrm{BI}$ therapy [28] (this treatment is represented by the term BI (2)). This RR for mortality for people who are alcohol dependent was obtained from the Cochrane review of all studies which had a 12 month follow-up [28].

The drinking population was modelled using 100,000 samples drawn from the Gamma distribution representing the drinking population of the UK. It was assumed that only heavier drinkers would receive interventions, as their identification as being alcohol dependent is more likely. The people with $\mathrm{AD}$ were, therefore, randomly selected among the samples displaying an average alcohol consumption of $72 \mathrm{~g}$ and $48 \mathrm{~g}$ of pure alcohol per day or more for men and women respectively. This lower limit was based on alcohol consumption among people with AD [30].

The number of deaths avoided under different treatment scenarios was calculated by estimating the number of alcohol-attributable deaths at the population level, assuming $0 \%$ of people with $\mathrm{AD}$ were receiving treatment, and then by comparing this estimate to a simulated population where $10 \%, 20 \%, 30 \%$ and $40 \%$ of people with $\mathrm{AD}$ were receiving $\mathrm{AD}$ treatment. Alcohol-attributable mortality was calculated by applying alcohol dose and disease specific relative risks for mortality to each of the 100,000 random samples (see Additional file 2 for the methodology used to estimate the mortality attributable to $\mathrm{AD}$ ).

The main analyses and sensitivity analyses using alternative $\mathrm{AD}$ prevalence data were performed using the above-described methods. The sensitivity analyses differ only with respect to the $\mathrm{AD}$ prevalence data that were used.

No ethics approvals were required, as our analyses were considered secondary data of existing databases.

\section{Results}

Impact of increasing treatment rates for AD on mortality Pharmacological therapy was the most effective intervention modelled at a AD treatment coverage rate of $20 \%$, with an estimated 794 deaths avoided in 2004 (173 deaths avoided among women and 621 deaths avoided among men), representing $7.9 \%$ of all alcohol-attributable deaths (7.0\% of all alcohol-attributable deaths for women and $8.1 \%$ of all alcohol-attributable deaths for men). The second and third most effective interventions at a coverage rate of $20 \%$ were MI/CBT (higher effectiveness), with an 
estimated 416 deaths avoided, and MI/CBT, with an estimated 348 deaths avoided respectively. The numbers of deaths avoided under the conditions that 10\%, 20\%, 30\% and $40 \%$ of people with $\mathrm{AD}$ were treated are outlined in Figure 1 for women and Figure 2 for men by AD treatment type. See Additional file 3 for the percentage of alcohol-attributable deaths prevented using the alternative AD prevalence rates.

\section{Sensitivity analyses}

If BI (modelled using a reduction in the risk of mortality, namely BI (2)) were implemented for $20 \%$ of the population, 832 deaths would be avoided in 2004 (158 deaths avoided for women and 674 deaths avoided for men), representing $8.2 \%$ of all alcohol-attributable deaths $(6.5 \%$ of all alcohol-attributable deaths for women and $8.8 \%$ of all alcohol-attributable deaths for men). The effects of BI were greater than those of any other intervention.

When the lower prevalences of $\mathrm{AD}$ and treatment coverage were modelled under the scenario where $20 \%$ of people with $\mathrm{AD}$ would be treated, pharmacological treatment was the most effective main intervention modelled (529 deaths avoided; 99 deaths avoided for women, and 430 deaths avoided for men), followed by MI/CBT (assuming a higher level of effectiveness) (264 deaths avoided), and then MI/CBT (217 deaths avoided). In the sensitivity analysis, BI (2) was the more effective than any of the main interventions modelled (547 deaths avoided). A summary of the comparison between the main and the alternative scenarios can be found in Figures 3 and 4 .

\section{Discussion}

$\mathrm{AD}$ is an important contributor to the burden of disease in the UK, and a large proportion of this burden could be reduced if the treatment coverage rate for $\mathrm{AD}$ was increased. Additionally, treatment of AD is important in the UK, as the burden of alcohol-attributable mortality is high [12] and has increased over the past 20 years in key categories such as liver disease [31]. Interestingly, even though overall average per capita consumption is the same in the UK as in the rest of the EU, the proportion of the burden of disease attributable to alcohol consumption is higher for men and even more so for women in the UK when compared to the rest of the EU $[3,12]$. This apparent contradiction may be due to the fact that people consume alcohol in the UK in a more detrimental manner than their EU counterparts [32].

An increase in $\mathrm{AD}$ treatment rates will not only impact mortality, but also will impact upon the large burden of disability and morbidity attributable to $\mathrm{AD}$, as well as the associated social and economic burdens [33-36]; however, increasing the treatment coverage for $\mathrm{AD}$ is non-trivial. One way to increase treatment coverage for AD is by increasing treatment options, such as offering the reduction of alcohol consumption as a treatment outcome [37]. A second way of increasing treatment coverage for $\mathrm{AD}$ is to reduce the stigma associated with $\mathrm{AD}$ [37]. The third way to increase treatment coverage is to ensure identification of individuals with $\mathrm{AD}$ when they come into contact with the medical system, such as during family physician (general practitioner) visits, and then be treated by a general practitioner for less severe cases of $\mathrm{AD}$ or referred to $\mathrm{AD}$ treatment services for more severe cases of AD [38]. All of these methods are difficult to implement and potentially costly $[38,39]$. Additionally, increasing treatment coverage of $\mathrm{AD}$ is not cost-effective when compared to other interventions, such as increasing taxation $[29,38,40]$. However, given the need to increase health equity as mandated by the World Health Organization, and the observation that people with $\mathrm{AD}$ are more likely to be members of a racial minority group and/or to have a low-income, increasing

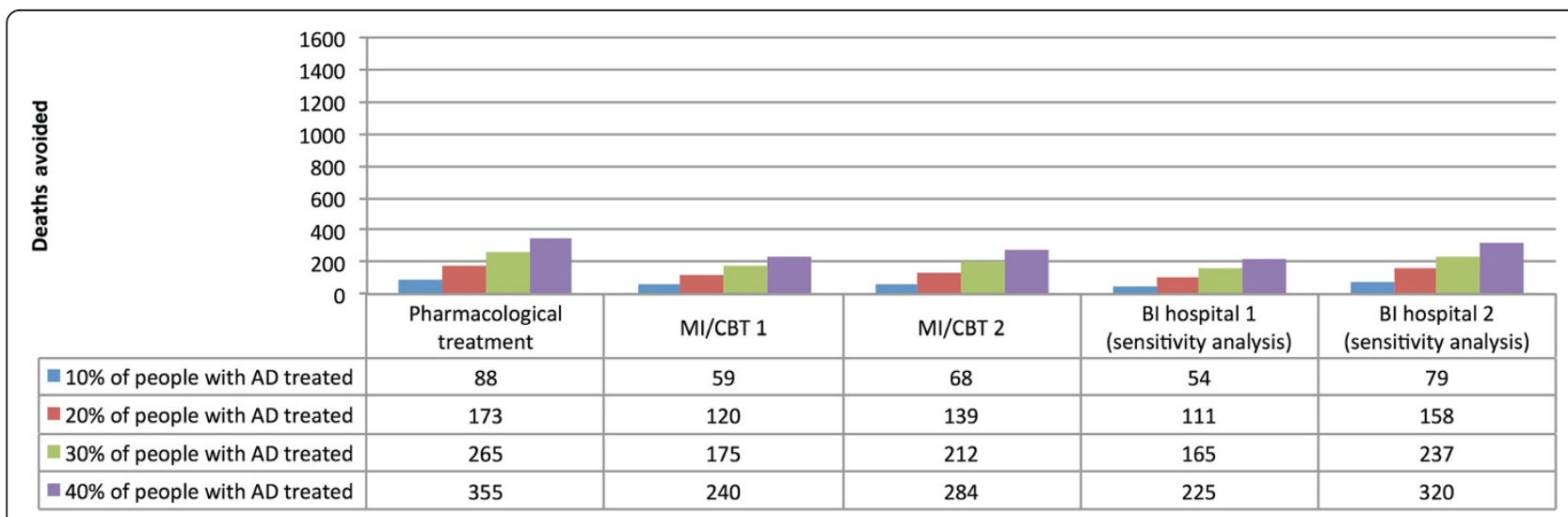

Figure 1 Deaths avoided in the UK for women based on different treatment coverage rates for AD for pharmacological treatment, Motivational Interviewing/Cognitive Behavioural (MI/CBT) (based on the lower (MBI/CT 1) and upper reported estimates (MBI/CT 2)), and Brief Interventions (BI) treatment (based on the resulting reduction in alcohol consumption (BI hospital 1) and the resulting reduction in mortality (BI hospital 2 )). 


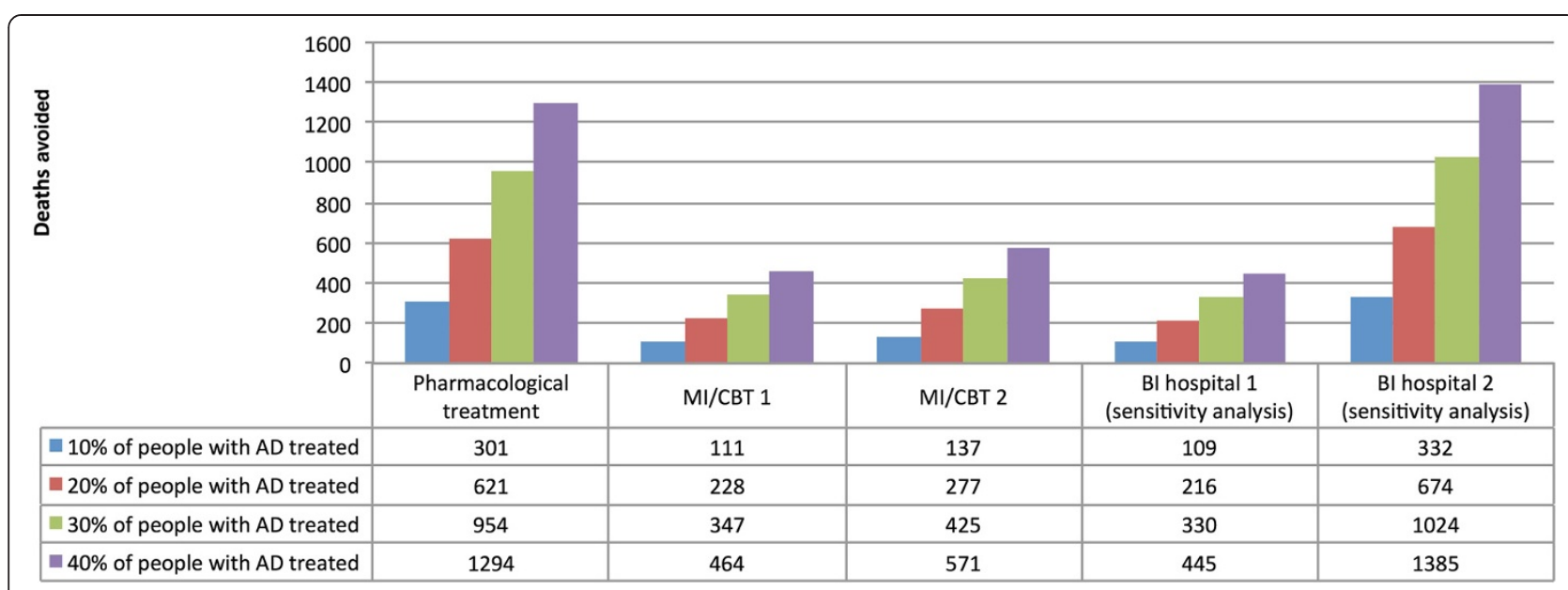

Figure 2 Deaths avoided in the UK for men based on different treatment coverage rates for AD for pharmacological treatment, Motivational Interviewing/Cognitive Behavioural (MI/CBT) (based on the lower (MBI/CT 1) and upper reported estimates (MBI/CT 2)), and Brief Interventions (BI) treatment (based on the resulting reduction in alcohol consumption (BI hospital 1) and the resulting reduction in mortality (BI hospital 2$)$ ).

$\mathrm{AD}$ treatment coverage rates is required from a health equity perspective [41].

\section{Limitations}

There are limitations to the methodology for the estimated number of deaths avoided if the treatment coverage for $\mathrm{AD}$ was increased to $40 \%$. First, the results for BI were based on male heavy drinkers (with some studies included in the meta-analysis excluding people with AD) and, thus, the applicability of these results to men and especially to women with $\mathrm{AD}$ is questionable [28]. However, it should be noted that the association between heavy drinking and
$\mathrm{AD}$ is strong [42], and heavy drinking has been suggested as main domain for the operationalization for alcohol use disorders [43].

Second, the high estimates of the effects of the BIs are based on the latest Cochrane analyses of seven randomized controlled clinical trials (RCTs) in hospitals [28]. It is plausible that a relatively short intervention can have a large effect in this population, as people in hospitals have higher risks of premature mortality, and the reduction of alcohol consumption in such a group has shown important effects on mortality (for an overview see [8]). Thus, BI in hospitals represents a "best case" scenario,

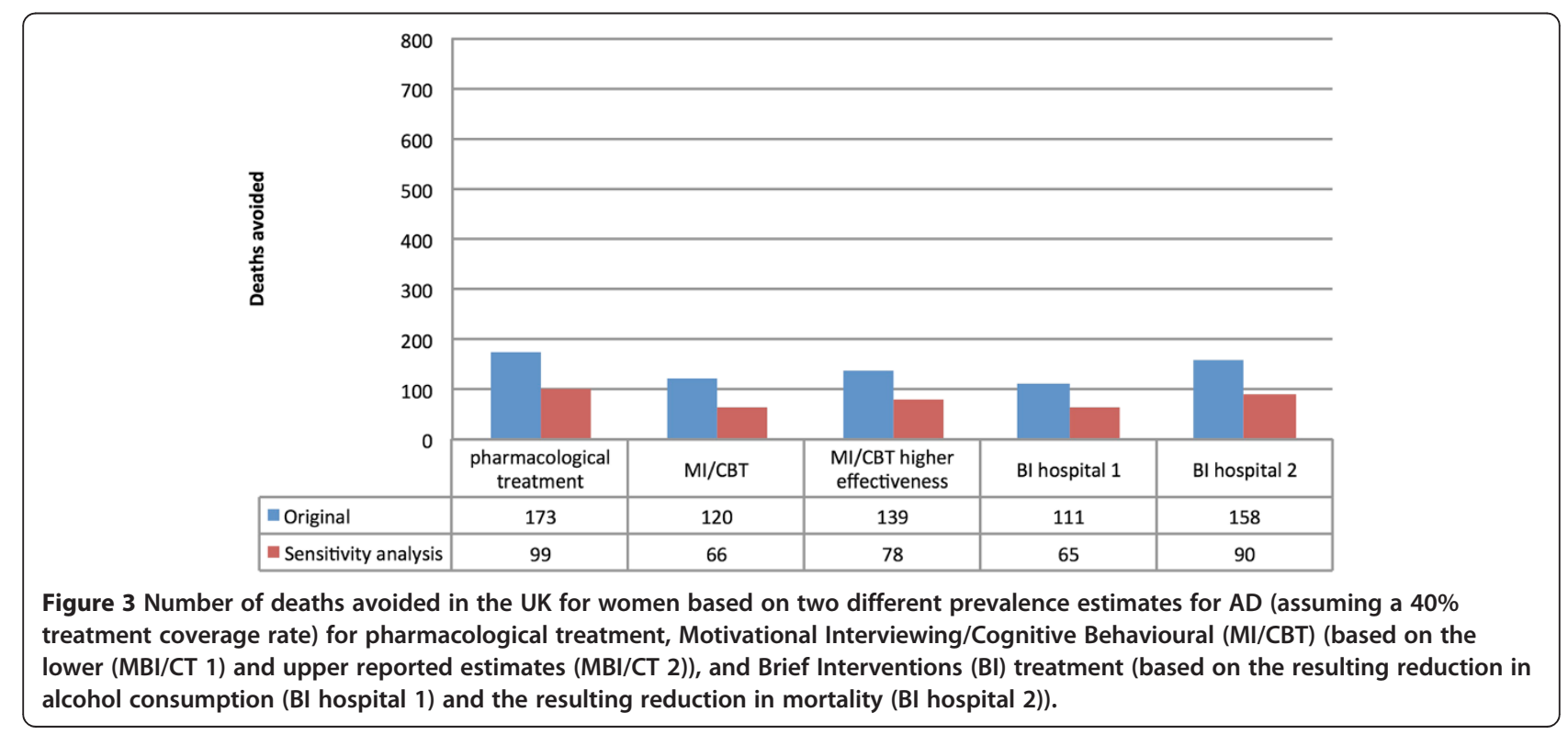




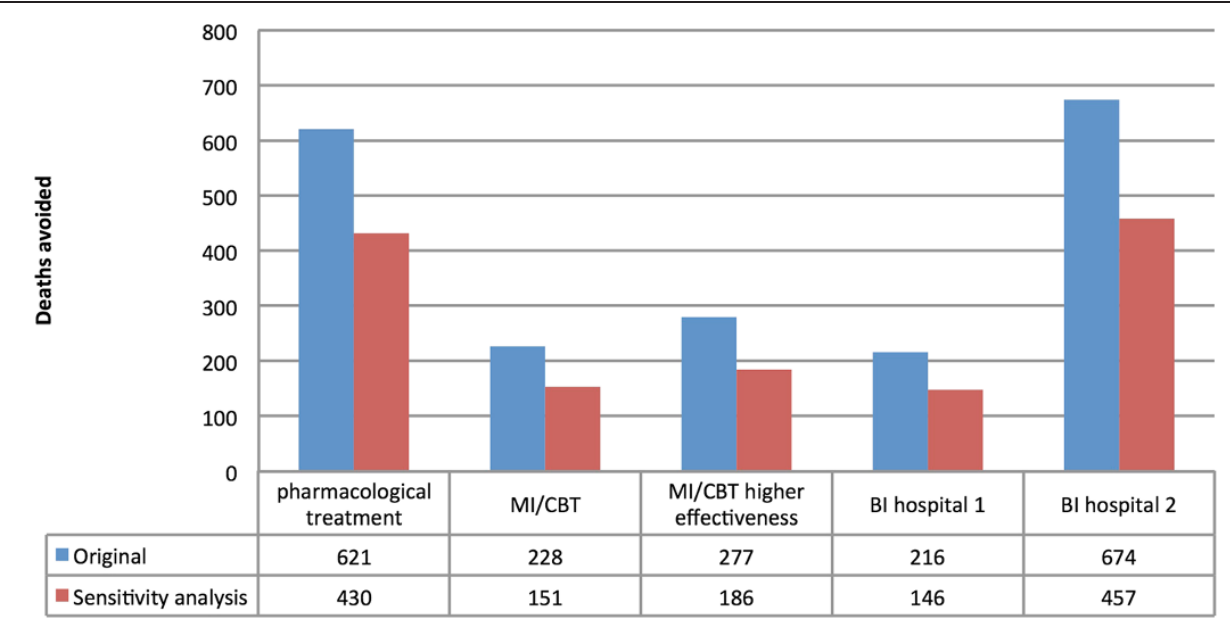

Figure 4 Number of deaths avoided in the UK for men based on two different prevalence estimates for AD (assuming a $40 \%$ treatment coverage rate) for pharmacological treatment, Motivational Interviewing/Cognitive Behavioural (MI/CBT) (based on the lower (MBI/CT 1) and upper reported estimates (MBI/CT 2)), and Brief Interventions (BI) treatment (based on the resulting reduction in alcohol consumption (BI hospital 1) and the resulting reduction in mortality (BI hospital 2)).

as $\mathrm{AD}$ treatment plays an important role in mediating and moderating premature mortality (e.g. $[44,45])$. However, effects on mortality were also observed in a metaanalyses of BIs in all settings and populations [46]. Therefore, we used the results from the meta-analysis by McQueen and colleagues on BIs as a sensitivity analysis only, as these results may not represent the actual number of deaths avoided if treatment coverage for BIs was increased [28].

The third limitation to our study is that even though overall average per capita consumption is the same in the UK as in the rest of the EU, the proportion of the burden of disease attributable to alcohol consumption is higher for men and even more so for women in the UK when compared to the rest of the $\mathrm{EU}[3,11]$. The reason for this contradiction may be due to the fact that people consume alcohol in the UK in a more detrimental manner than their EU counterparts [34]. Additionally, this study modelled only the effect of increasing the treatment coverage rate for $\mathrm{AD}$ on mortality. Increasing $\mathrm{AD}$ treatment rates will also impact the large burden of disability and morbidity attributable to $\mathrm{AD}$, as well as the associated social and economic burdens [35-38]. Fourth, while we estimated the effects for one year, most of the RCTs had smaller follow-up times, and the effects may not be as strong for one year. This may especially affect the psychotherapies, but does not affect the estimated reduction in the $\mathrm{RR}$ of mortality from $\mathrm{BI}$ in hospitals as this reduction was based only on RCTs with a follow-up of one year. This limitation may be as a result of differences between efficacy and effectiveness [47-49] of trials, i.e., not all of the effects seen in RCTs in selected populations may transfer into the real world (see also [50]). Additionally, it is unclear if BI would be as effective if the coverage of alcohol interventions was increased to $40 \%$ of the population with $\mathrm{AD}$, a proportion of whom may be less motivated to engage in the interventions offered compared to those currently receiving treatment.

A fifth limitation is the feasibility of increasing the treatment rate to $40 \%$, as a similar coverage rate has not been achieved in any other similar high-income country [3]. The final limitation to our study is that the analysis was limited to single AD interventions, and the effects of combination therapies have not been examined through a meta-analysis [3].

\section{Conclusions}

The burden of mortality attributable to alcohol consumption in the UK is large, and has been increasing over the past 20 years in key categories such as liver cirrhosis. A large proportion of the burden of disease in the UK is attributable to unhealthy patterns of alcohol consumption and to AD. Based on the analysis of data for 2004, this article presents observations that an increase in AD treatment in the UK could lead to the prevention of a large number of deaths.

\section{Additional files}

Additional file 1: Modelling the effects of $A D$ interventions. Additional file 2: Modelling mortality attributable to alcohol consumption. 
Additional file 3: Percentage of all alcohol-attributable deaths avoided by increasing AD treatment coverage to $20 \%$ (sensitivity analyses).

\section{Abbreviations}

AD: Alcohol dependence; Bl: Brief interventions; Cl: Confidence interval; EU: European Union; GBD: Global burden of disease; g: grams; I: litre(s); MI/CBT: Motivational interviewing/cognitive behavioural therapy; RCT: Randomized controlled clinical trials; RR: Relative risk; UK: United Kingdom.

\section{Competing interests}

Lundbeck provided financial support for this study via an unrestricted grant. Lundbeck had no influence on the data gathering or design of this study. In the past few years Jürgen Rehm has received unrestricted grants from Eli Lilly, Schering-Plough, and Lundbeck, and is a member of the scientific advisory council for Nalmefene.

\section{Authors' contributions}

JR and CD conceptualized the overall article. KDS, JR, MXR, and GG acquired all data. All authors contributed to the methodology. KS and GG performed all statistical analyses. All authors contributed to the writing of the manuscript and approved the final version.

\section{Acknowledgements}

Lundbeck provided financial support for this study via an unrestricted grant. Dr. Rehm acknowledges funding support from a CIHR Team Grant (\#SAF195814), as well as from the Ontario Ministry of Health and Long-Term Care.

\section{Author details}

${ }^{1}$ Centre for Addiction and Mental Health (CAMH), 33 Russell Street, Toronto, ON M5S 2S1, Canada. Institute of Medical Science, University of Toronto, Toronto, Canada. ${ }^{3}$ Institute for Clinical Psychology and Psychotherapy, TU Dresden, Germany. ${ }^{4}$ Dalla Lana School of Public Health (DLSPH), University of Toronto, Toronto, Canada. ${ }^{5}$ Department of Psychiatry, University of Toronto, Toronto, Canada. ${ }^{6}$ Faculty of Arts and Sciences/Politics and Governance, Ryerson University, Toronto, Toronto, Canada. ${ }^{7}$ National Addiction Centre, Institute of Psychiatry, King's College London, London, UK.

Received: 18 March 2013 Accepted: 7 January 2014

Published: 5 February 2014

\section{References}

1. Lim SS, Vos T, Flaxman AD, Danaei G, Shibuya K, Adair-Rohani H, Amann M, Anderson HR, Andrews KG, Aryee M, Atkinson C, Bacchus L, Bahalim AN, Balakrishnan K, Balmes J, Barker-Collo S, Baxter A, Bell ML, Blore JD, Blyth F, Bonner C, Borges G, Bourne R, Boussinesq M, Brauer M, Brooks P, Bruce NG, Brunekreef B, Bryan-Hancock C, Bucello C, et al: A comparative risk assessment of burden of disease and injury attributable to 67 risk factors and risk factor clusters in 21 regions, 1990-2010: a systematic analysis for the Global Burden of Disease Study 2010. Lancet 2012, 380:2224-2260.

2. Rehm J, Mathers C, Popova S, Thavorncharoensap M, Teerawattananon Y, Patra J: Global burden of disease and injury and economic cost attributable to alcohol use and alcohol use disorders. Lancet 2009, 373(9682):2223-2233.

3. Rehm J, Shield KD, Rehm MX, Gmel G, Frick U: Modelling the impact of alcohol dependence on mortality burden and the effect of available treatment interventions in the European Union. Eur Neuropsychopharmacol 2013, 23(2):89-97.

4. Ezzati M, Lopez A, Rodgers A, Murray CJL: Comparative quantification of health risks. Global and regional burden of disease attributable to selected major risk factors. Geneva, Switzerland: World Health Organization; 2004.

5. American Psychiatric Association: Diagnostic and statistical manual of mental disorders (4th edition, text revision). Washington, DC: American Psychiatric Association; 2000.

6. Dawson DA, Li TK, Grant BF: A prospective study of risk drinking: at risk for what? Drug Alcohol Depend 2008, 95:62-72.
7. Li TK, Hewitt BG, Grant BF: The alcohol dependence syndrome, 30 years later: a commentary. The 2006H. David Archibald lecture. Addiction 2007, 102(10):1522-1530.

8. Rehm J, Shield KD, Rehm MX, Gmel G Jr, Frick U: Alcohol Consumption, Alcohol Dependence, and Attributable Burden of Disease in Europe: Potential Gains from Effective Interventions for Alcohol Dependence. Toronto, Canada: Centre for Addiction and Mental Health; 2012.

9. European Commission: EU citizens' Attitudes Towards Alcohol. Special Eurobarometer 331. Brussels, Belgium: TNS; 2010.

10. Bebbington P, Brugha T, Coid J, Crawford M, Deverill C, D'Souza J, Doyle M, Farrell M, Fuller E, Jenkins R, Jotangia D, Harris J, Hussey D, King M, McManus S, Meltzer H, Nicholson S, Palmer B, Pickup D, Purdon S, Sadler K, Scholes S, Smith J, Thompson J, Tyrer P, Wardle H, Weich S, Wessely S: Adult Psychiatric Morbidity in England, 2007. England, UK: The Health \& Social Care Information Centre - Social Care Statistics; 2009.

11. Drummond C, Pilling S, Brown A, Copello A, Day E, Dervan J, Dyer M, Flanagan E, Fry J, Georgeson B, Gilvarry E, Glover N, Gosnall J, Harris L, Lewis JW, Lingford Hughes AR, Mavranezouli I, Mccarthy T, Morgan M, Noble S, Omarjee S, Phillips T, Roberts P, Satrettin R, Shields L, Sinclair J, Stockton S, Taylor C, Yesufu-Udechuku A: Alcohol use Disorders: Diagnosis, Assessment and Management of Harmful Drinking and Alcohol Dependence. London: National Institute for Health and Clinical Excellence; 2011.

12. Shield KD, Kehoe T, Gmel G, Rehm MX, Rehm J: Societal burden of alcohol. In Alcohol in the European Union Consumption, Harm and Policy Approaches. Edited by Anderson P, Møller L, Galea G. Copenhagen, Denmark: World Health Organization Regional Office for Europe; 2012:10-28.

13. Martin $G$, Rehm J: The effectiveness of psychosocial modalities in the treatment of alcohol problems in adults: a review of the evidence. Can J Psychiatry 2012, 57(6):350-358.

14. Rösner $\mathrm{S}$, Hackl-Herrwerth $A$, Leucht $S$, Lehert $P$, Vecchi S, Soyka M: Acamprosate for alcohol dependence. Cochrane Database Syst Rev 2010, 9. CD004332.

15. Rösner S, Hackl-Herrwerth A, Leucht S, Vecchi S, Srisurapanont M, Soyka M: Opioid antagonists for alcohol dependence. Cochrane Database Syst Rev 2010, 12, CD001867.

16. Alonso J, Angermeyer MC, Bernert S, Bruffaerts R, Brugha TS, ESEMeD/ MHEDEA Investigators: Use of mental health services in Europe: results from the European Study of the Epidemiology of Mental Disorders (ESEMeD) project. Acta Psychiatr Scand 2004, 109(420):47-54

17. Drummond DC, Oyefeso N, Phillips T, Cheeta S, DeLuca P, Perryman K, Winfield H, Jenner J, Cobain K, Galea S, Saunders V, Fuller T, Pappalardo D, Baker O, Christopolous A: Alcohol Needs Assessment Research Project: The 2004 National Alcohol Needs Assessment for England. London: Ministry of Health; 2005.

18. Drummond C, Deluca P, Oyefeso A, Rome A, Scrafton S, Rice P: Scottish Alcohol Needs Assessment. London: King's College London; 2009.

19. World Health Organization: Global Status Report on Alcohol and Health. Geneva, Switzerland: World Health Organization; 2011.

20. Shield K, Rylett M, Gmel G, Gmel G, Kehoe-Chan T, Rehm J: Global alcohol exposure estimates by country, territory and region for 2005 - a contribution to the comparative risk assessment for the 2010 global burden of disease study. Addiction 2013, 108(5):912-922.

21. Rehm J, Rehn N, Room R, Monteiro M, Gmel G, Jernigan D, Frick U: The global distribution of average volume of alcohol consumption and patterns of drinking. Eur Addict Res 2003, 9(4):147-156.

22. Rehm J, Kehoe T, Gmel G, Stinson F, Grant B, Gmel G: Statistical modeling of volume of alcohol exposure for epidemiological studies of population health: the example of the US. Popul Health Metr 2010, 8:3.

23. Kehoe T, Gmel G Jr, Shield K, Gmel G Sr, Rehm J: Determining the best population-level alcohol consumption model and its impact on estimates of alcohol-attributable harms. Popul Health Metr 2012, 10(1):6.

24. Rothman KJ, Greenland S, Lash TL: Modern Epidemiology. 3rd edition. Philadelphia, PA: Lippincott Williams \& Wilkins; 2008.

25. Smedslund G, Berg RC, Hammerstrom KT, Steiro A, Leiknes KA, Dahl HM, Karlsen K: Motivational interviewing for substance abuse. Cochrane Database Syst Rev 2011, 5, CD008063.

26. Magill M, Ray LA: Cognitive-behavioral treatment with adult alcohol and illicit drug users: a meta-analysis of randomized controlled trials. J Stud Alcohol Drugs 2009, 70(4):516-527. 
27. Project Match Research Group: Matching alcoholism treatment to client heterogeneity: project MATCH posttreatment drinking outcomes. J Stud Alcohol 1997, 58:7-30.

28. McQueen J, Howe TE, Allan L, Mains D, Hardy V: Brief interventions for heavy alcohol users admitted to general hospital wards. Cochrane Database Syst Rev 2011, 8, CD005191.

29. Room R, Babor T, Rehm J: Alcohol and public health: a review. Lancet 2005, 365:519-530.

30. Grant BF, Dawson DA: Introduction to the National Epidemiologic Survey on alcohol and related conditions. Alcohol Res Health 2006, 29:74-78,

31. Leon DA, McCambridge J: Liver cirrhosis mortality rates in Britain from 1950 to 2002: an analysis of routine data. Lancet 2006, 367(9504):52-56.

32. Plant M, Plant M: Binge Britain. Alcohol and the National Response. Oxford, U.K.: Oxford University Press; 2006.

33. Mohapatra S, Patra J, Popova S, Duhig A, Rehm J: Social cost of heavy drinking and alcohol dependence in high-income countries. Int J Public Health 2010, 55(3):149-157.

34. Science Group of the European Alcohol Health Forum: Alcohol, Work and Productivity. Brussels: EU Alcohol and Health Forum; 2011.

35. Anderson P, Baumberg B: Alcohol in Europe: a Public Health Perspective. A Report of the European Commission. London, UK: Institute of Alcohol Studies; 2006.

36. Paparrigopoulos T, Tzavellas E, Karaiskos D, Stefanis N, Mourikis I, Stahtea X Liappas J: Family burden in alcohol dependence. Eur Psychiatry 2009, 24:449.

37. Rehm J, Rehm MX, Alho H, Allamani A, Aubin H-J, Bühringer G, Daeppen JB, Frick U, Gual A, Heather N: Alcohol dependency treatment in the EU: a literature search and expert consultation about the availability and use of guidelines in all EU countries plus Iceland, Norway, and Switzerland. Int J Alcohol Drug Res 2013. epub ahead of print April 25.

38. Babor T, Caetano R, Casswell S, Edwards G, Giesbrecht N, Graham K, Grube J, Gruenewald P, Hill L, Holder H, Homel R, Livingston M, Österberg E, Rehm J, Room R, Rossow I: Alcohol: No Ordinary Commodity. Research and Public Policy. 2nd Edition. Oxford and London: Oxford University Press; 2010

39. Anderson P, Chisholm D, Fuhr D: Effectiveness and cost-effectiveness of policies and programmes to reduce the harm caused by alcohol. Lancet 2009, 373(9682):2234-2246.

40. Bloom DE, Chisholm D, Jane-Llopis E, Prettner K, Stein A, Feigl A: From Burden to" Best Buys": Reducing the Economic Impact of Non-Communicable Disease in Low-and Middle-Income Countries. Geneva, Switzerland: World Economic Forum; 2011.

41. World Health Organization: Equity, Social Determinants and Public Health Programmes. Geneva, Switzerland: World Health Organization; 2010.

42. Rehm J, Anderson P, Gual A, Kraus L, Marmet S, Room R, Samokhvalov A, Scafato E, Shield K, Trapencieris M, Wiers R, Gmel G: The tangible common denominator of substance use disorders: a reply to commentaries to Rehm et al.(2013). Alcohol Alcohol 2014, 49(1):118-122.

43. Rehm J, Marmet S, Anderson P, Gual A, Kraus L, Nutt DJ, Room R, Samokhvalov AV, Scafato E, Trapencieris M, Wiers RW, Gmel G: Defining substance use disorders: do we really need more than heavy use? Alcohol Alcohol 2013, 48(6):633-640.

44. De Lorenze GN, Weisner C, Tsai AL, Satre DD, Quesenberry CP Jr: Excess mortality among HIV-infected patients diagnosed with substance use dependence or abuse receiving care in a fully integrated medical care program. Alcohol Clin Exp Res 2011, 35(2):203-210.

45. O'Brien JM Jr, Lu B, Ali NA, Martin GS, Aberegg SK, Marsh CB, Lemeshow S, Douglas IS: Alcohol dependence is independently associated with sepsis, septic shock, and hospital mortality among adult intensive care unit patients. Crit Care Med 2007, 35(2):345-350.

46. Cuijpers $P$, Riper $H$, Lemmers $L$ : The effects on mortality of brief interventions for problem drinking: a meta-analysis. Addiction 2004, 99(7):839-845.

47. Carroll KM, Rounsaville BJ: A vision of the next generation of behavioral therapies research in the addictions. Addiction 2007, 102(6):850-862.

48. Hollon SD: The efficacy and effectiveness of psychotherapy relative to medications. Am Psychol 1996, 51(10):1025-1030.
49. Nathan PE, Scott SP, Dolan SL: Research on psychotherapy efficacy and effectiveness: between Scylla and Charybdis? Psychol Bull 2000, 126(6):964-981.

50. Kaner E, Bland M, Cassidy P, COulton S, Dale V, Deluca P, Gilvarry E, Godfrey C, Heather N, Myles J, Newbury-Birch D, Oyefeso A, Parrott S, Perryman K, Phillips T, Shenker D, Shepherd J, Drummond C: Pragmatic cluster randomised controlled trial of the effectiveness and cost-effectiveness of screening and brief alcohol intervention in primary care in England. BMJ 2012, 346:e8501.

doi:10.1186/1472-6963-14-53

Cite this article as: Shield et al:: The potential impact of increased treatment rates for alcohol dependence in the United Kingdom in 2004 BMC Health Services Research 2014 14:53.

\section{Submit your next manuscript to BioMed Central and take full advantage of:}

- Convenient online submission

- Thorough peer review

- No space constraints or color figure charges

- Immediate publication on acceptance

- Inclusion in PubMed, CAS, Scopus and Google Scholar

- Research which is freely available for redistribution

Submit your manuscript at www.biomedcentral.com/submit
C) Biomed Central 